Joumat of

Sîraiegic ivianagemeni (JSM)

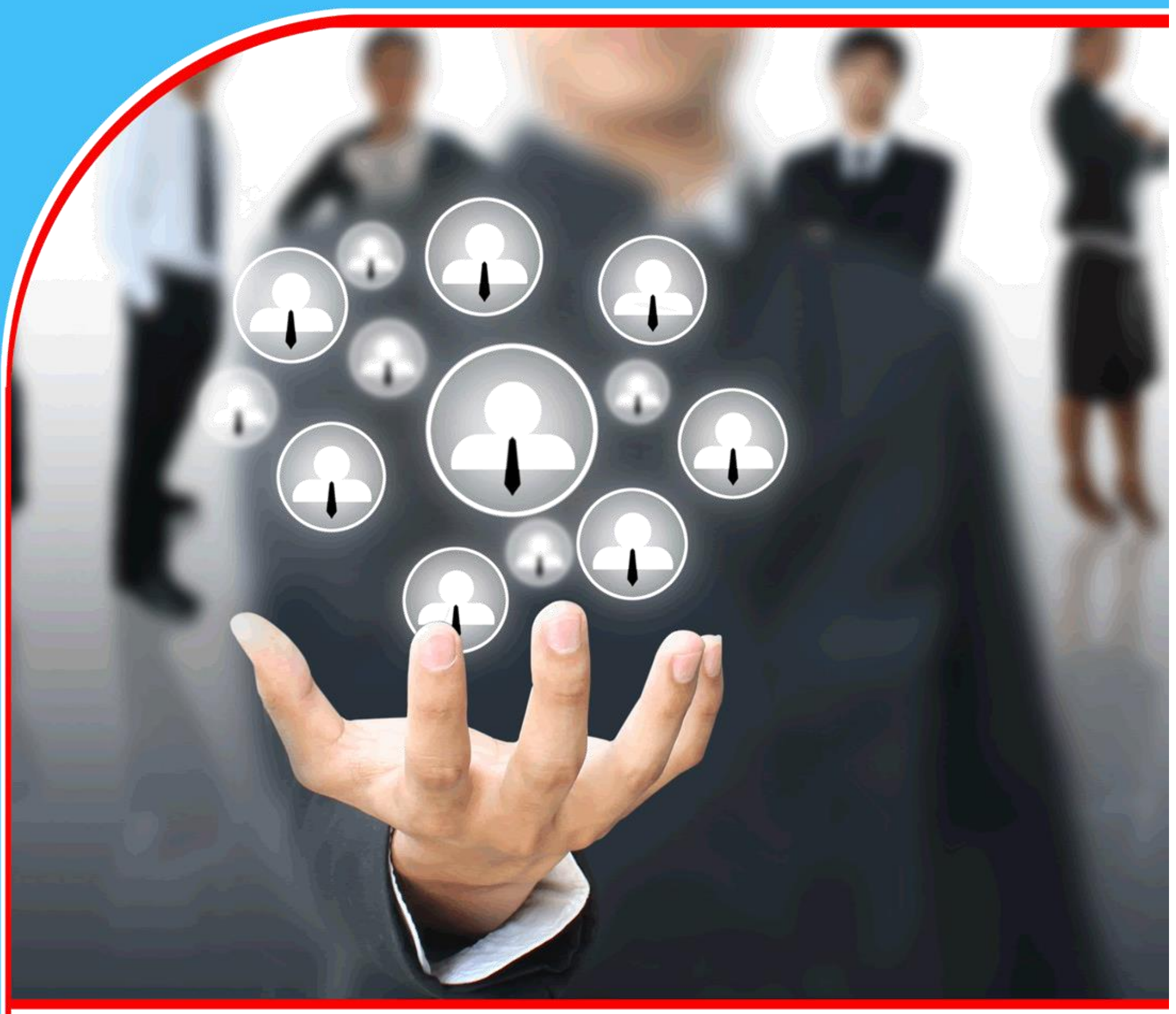

ASSESSMENT OF CHALLENGES FACING THE IMPLEMENTATION OF THE COUNTY INTEGRATED DEVELOPMENT PLAN: A CASE STUDY OF NAROK COUNTY GOVERNMENT Jane Tipitip Psiwa, Duncan Irungu and Samuel Muriithi

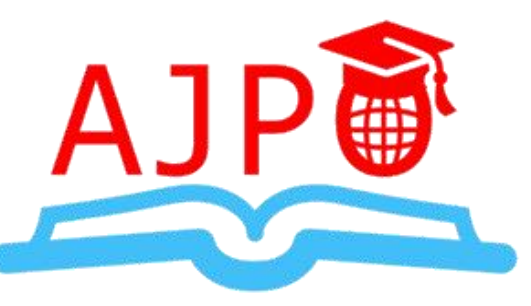




\title{
ASSESSMENT OF CHALLENGES FACING THE IMPLEMENTATION OF THE COUNTY INTEGRATED DEVELOPMENT PLAN: A CASE STUDY OF NAROK COUNTY GOVERNMENT
}

\author{
1* Jane Tipitip Psiwa \\ ${ }^{1 *}$ Post graduate student, Daystar University \\ *Corresponding Author's Email:steve@gmail.com \\ 2* Duncan Irungu \\ Lecturer, Daystar University \\ 3* Samuel Muriithi \\ Lecturer, Daystar University
}

\begin{abstract}
Purpose: The purpose of this study was to assess challenges facing the implementation of the County Integrated Development Plan (CIDP) in Narok County Government.

Methodology: The study utilized a descriptive survey research design. The target population comprised of 10 County Executive Committee Members, 22 County Chief Officers who report to CECs and 62 directorates of the respective functional sections or units of the government in Narok County. The study utilized a census technique of data collection meaning the target population was studied.
\end{abstract}

Results: The major findings of the study were that NCG employees were involved in the formulation of the CIDP, the CIDP had been implemented to a moderate extent, NCG had met less than $50 \%$ of the performance targets as well as less than $50 \%$ CIDP development projects or interventions, the CIDP of NCG is comprehensive as per the requirements of the constitution of Kenya 2010, NCG indeed experienced financial-related challenges, human resource-related challenges and leadership-related challenges in the process of implementing the CIDP. The findings also revealed that national government policies and legislation and organization culture influenced the implementation of the CIDP.

Unique contribution to theory, practice and policy: the study recommends that the national government of Kenya should disburse funds to the county governments regularly and on time, NCG should review their style of leadership to a transformational and consultative style, and that the national government should review the national legislations and policies that govern the operations of county governments.

Key words: Implementation, development plan, challenges 


\subsection{INTRODUCTION}

\subsection{Background of the Study}

An integrated development plan is a strategic plan (Mbambisa, 2014). According to David (2013), a strategic plan is in essence an organization's game plan that enables it to gain and maintain competitive advantage. Strategic plans are considered to be very important in the management and success of organizations. Strategic planning is a management tool that helps an organization to improve its performance by ensuring that its members are working towards the same goals and continuously adjusting the direction of the organization to the changing environment on the basis of obtained results. According to Covin, Slevin, and Schulz (2004), strategic planning is sensitive to the environment and therefore it should be based on the belief that the successful development of an organization is the result of finding the right fit between its internal strengths and weaknesses and the external opportunities and threats stemming from the environment.

Strategic planning typically involves a process of planning which results in the organization's strategic plan (Liedtka, 2008). Likewise, Greenberg and Baron (2010) defined strategic planning as "the process of formulating, implementing, and evaluating decisions that enable an organization to achieve its objectives." (p. 633). Similarly, David (2013) described strategic planning as the art and science of formulating, implementing, and evaluating cross functional decisions of management, marketing, finance, operations or production, research and information systems to achieve organizational success.

Implementation of strategic plans is vital to any organization because it determines the success or failure of the organization. Organizations use strategy to determine goals and objectives. The strategies assist to identify necessary courses of action and allocation of resources necessary to achieve the set goals (Alexander, 2001). Organizations often fail to operationalize their strategies in ways that improve the likelihood that they will be implemented effectively. Kaplan and Beinhocker (2003) stated that challenges in strategic plans implementation mainly rotate on individual barriers such as too many and conflicting priorities, insufficient top team functions, a top down management style, inter functional conflicts, poor vertical communication and inadequate management development. Beinhocker (2003) also posited that financial barriers to strategy implementation include budget restrictions limiting the overall expenditure on the strategy, financial restrictions on specific instruments, and limitations on the flexibility with which revenues can be used to finance the full range of instruments.

Integrated development planning is vital since communities cannot develop and grow in isolation. The integrated development plans involve public participation programmes, stakeholder engagement and planning which ensures that the needs for the citizens are met. These needs include, job creation, roads, electricity, health, education, business empowerment and support, and sport and recreational facilities. These needs and priorities highlight the fact that the local government is not the only role-player in attaining a better life for citizens; County and National Government also have a role to play. This reaffirms the critical need for the County Government to strengthen its engagements with all stakeholders involved in the development process (Mbambisa, 2014).

The Integrated Development Plan (IDP) seeks to synergize and advance opportunities made towards the realization of the goal of a better life for all citizens in a country. It also ensures close co-ordination and integration between projects, programmes, activities and the budget, both internally (between directorates) and externally (with other spheres of government). The 
IDP ultimately enhances integrated service delivery and development and promotes sustainable, integrated communities, providing a full basket of services, as communities cannot be developed in a fragmented manner (Mbambisa, 2014).

In a bid to spur economic growth, the Kenyan government has over time formulated several development strategic plans. These development strategic plans include Economic Recovery Strategy for Wealth Creation and Employment 2003-2007, The Kenya Economic Stimulus Program (ESP) of 2009/2010 and the County Integrated Development Plan of 2013-2017. Specifically, the CIDP is anticipated to help fulfil Kenya vision 2030 goals. The vision 2030 is being implemented in successive five-year medium term plans (MTPs), with the second plan covering 2013-2017. During each medium term plan the counties are expected to contribute towards realization of average gross domestic product (GDP) growth rate of $10 \%$ per annum in line with the economic goal of Kenya Vision 2030.

\subsection{Statement of the Problem}

A devolved system of government and county governments are new in the republic of Kenya. This entails decentralization of power so that governance and the corresponding resources are devolved from the national (central) government to the decentralized county governments. The County Integrated Development Plan (CIDP) provides an overall coordinated framework for development. The significant role that CIDPs play in the administration and management of county governments must not be under estimated (Kenya Devolution, 2015). The Constitution of Kenya (2010) has pointed out that devolution is geared towards bringing service delivery closer to the people. However, like all new systems of governance, devolution in Kenya has been marred with a myriad of challenges that has seen a huge outcry in the Kenyan media over the management of county governments, and Narok County Government is no exception. An evaluation of the progress report on implementation of the CIDP reveals that Narok County Government has fallen short of achieving its strategic objectives (IBP, 2015).

Narok County Government has faced a myriad of challenges. These challenges include financial-related challenges, human resource-related challenges and leadership-related challenges. The financial-related challenges arise from insufficiency of funds as well delay of disbursement of funds from the national government. The county also experiences leadershiprelated challenges whereby some of the leaders in key positions are not professional which dampens the operations of the county government. Further, the issue of lack of professional leaders breeds the human resource-related challenges which also hinder effective implementation of the CIDP (County Government of Narok M \& E Reports, 2013-2015). This report is supported by Kaplan and Beinhocker (2003) who stated that challenges in strategic plans implementation mainly rotate on individual barriers such as too many and conflicting priorities, insufficient top team functions, a top down management style, inter functional conflicts, poor vertical communication and inadequate management development.

\subsection{Objectives of the Study}

The specific objectives of the study were

i. To assess the extent to which County Integrated Development Plan (CIDP) in Narok County Government has been implemented.

ii. To establish the financial-related challenges facing the implementation of the County Integrated Development Plan (CIDP) in Narok County Government.

iii. To establish the human resource-related challenges facing the implementation of the 
County Integrated Development Plan (CIDP) in Narok County Government.

iv. To establish the leadership-related challenges facing the implementation of the County Integrated Development Plan (CIDP) in Narok County

\subsection{LITERATURE REVIEW}

\subsection{Theoretical Framework}

\subsubsection{Resource-Based View Theory}

This theory argues that firms possess resources which enable them to achieve competitive advantage and lead to superior long term performance. Valuable and rare resources can lead to the creation of competitive advantage. That advantage can be sustained over longer time periods to the extent that the firm is able to protect against resource limitation, transfer or substitution (Frawley \& Fahy, 2006). Information system resources may take on many of the attributes of dynamic capabilities and may be useful to firms operating in rapidly changing environments. Information resources may not directly lead the firm to a position of superior sustained competitive advantage but may be critical to the firm's long term competitiveness in unstable environments. They ensure firm's long term competitiveness through helping them to develop, add, integrate and release other key resources over time (Wade \& Hulland, 2004).

Resources such as adequate finance and competent and skilled managers are crucial for effective management practices in a rapidly changing environment (Wade \& Hulland, 2004). The dynamic capabilities which consist of the activities and mechanisms of managing resources in the creation of value may have an influence on the effectiveness and success of youth enterprise projects within the country. It is expected that an organization that has adequate financial resources would facilitate effective/successful management practices. This theory was relevant to the study as it explained how resources at a firm's disposal are a critical factor for effective management. In the context of this study, proper utilization of available resources would result to effective integrated development plan implementation.

\subsubsection{Electric Implementation Theory}

This theory suggests that a successful strategy implementation is a function of variables that in theory have been developed and studied separately but in practice must be fully integrated. The integration of such variables defines the implementation process. The degree of usefulness of the process on the other hand is driven by at least six criteria. An implementation process (or model) increases its value if at least it is logical, operational, economical, balanced, manageable and efficient (Jofre, 2011).

Logic is necessary to build an implementation process within a rational framework that is meaningful to the organization. Logic also allows deductive construction from which further implementation activities or sequences are derived. Logic is not entirely based on experience or instinct but also in facts which allow development of an implementation framework that combines both theory and practice. A useful model for implementation should, in addition to logic, be expressed in terms of operational and concrete actions that are tangible and verifiable or that at least are meaningful and objective. By doing so, the model allows the introduction of greater change by identifying or solving more issues (Jofre, 2011).

In this context, implementation should be economic or frugal, or in other words, capable to address a complex process with a minimum number of variables. If the model is also capable to balance theory and practice, as well as facts and assumptions, then it will allow a more 
accurate implementation. A model should not be a recipe of what to do but also of about the implications of doing. This regards the balance between the contingency (eventualities) and the prescription (directions) perspective, or in other words the reconciliation between theories and laws (Jofre, 2011).

One of the most difficult tasks when implementing strategies is that decision-making occurs in a context of complexity and uncertainty. Hence, a useful implementation model should make sense of complexity and uncertainty and thus manageable according to the limitations of our cognitive capabilities. Efficiency implies that decision and actions should not only deal with complexity but also with constraints or limits to available resources and capabilities. In the perspective of efficiency, at least three forms are depicted: economic, cognitive and ethical efficiency. Economic efficiency is the most known of these forms and regards the development of actions with the least financial cost as possible (Jofre, 2011). This theory was relevant to the study in that it outlined the important aspects that should be considered when formulating a plan or model. A plan is evaluated upon this aspects and it is deemed successful or unsuccessful. Narok County Government can use this theory to evaluate their CIDP in a bid to increase its efficiency.

\subsection{Empirical Review}

Polle (2012) explored the responses by audit firms as to the challenges they face in implementing strategy. The study used descriptive design in its methodology and adopted a cross sectional survey approach where the units to be studied were audit firms in Nairobi. The population of the study was 619 audit firms. A sample of 60 audit firms was randomly selected, representing $10 \%$ of the target population. Data was analysed using descriptive statistics using means and frequencies. The study found that there are several challenges facing audit firms in the implementation of strategy, mostly due to insufficient financial resources and that the audit firms are not only technical efficient but have also embraced technology in their operations.

A study by Busaka and Kwasira (2015) sought to establish the challenges influencing strategy implementation in public sector organizations. The study targeted all 115 managers and gambling inspectors of Betting Control and Licensing Board. The study employed a descriptive research design using both qualitative and quantitative approaches. The study used close ended questionnaires to collect data using simple random sampling. Results revealed a fairly strong positive relationship between availability of financial resources and strategy implementation $(\mathrm{r}=0.593)$. Results also showed that there was a fairly weak positive relationship between information technology and strategy implementation $(r=0.327)$. Financial resources were found to be the most important factor in enhancing strategy implementation while the least factor was information technology.

Akwara (2010) investigated the challenges of strategy implementation at the Ministry of Cooperative Development and Marketing in Kenya. A case study research design was used to conduct the study and an interview guide administered to the heads of departments. The study findings revealed that the organizational culture, Human resource policy, financial resources policies and procedures, information and operating systems and performance incentives were all an impediment to strategy implementation. The Ministry of Co-operative Development and Marketing response to these challenges has been minimal and therefore the researcher recommends involvement of all relevant stakeholders in strategy implementation; sourcing for funds from other sources to supplement Ministry of Finance; budgeting in order of priority; establish a Ministerial taskforce to harmonize departmental policies and procedures; 
revise the human resource policy to make it more responsive; introduce rewards and recognition policy for excellent performers; develop a communication policy; and formulate a monitoring and evaluation policy.

A study by Kirui (2013) sought to investigate the significant institutional factors that influenced the overall push of the authorities to their pre-determined strategic goals. The thematic focus was on organizational culture, structure, leadership and financial resources. Towards achieving this, the study purposively targeted a case of Migori County to form a basis for objective generalization. The county had five local authorities which constituted the target population of 180 staffers. Sampling was conducted by proportional stratified sampling to generate ultimate respondents of 90 whose views and opinions led to the study's generalizations. From the identified respondents/informants, interviews and questionnaires were administered to collect the required data, which was processed and analyzed using descriptive statistics and content analysis.

Ackel, Kidombo and Gakuu (2012) noted that the nature and composition of the project team is an important aspect. Their findings show that the project teams performed contractual functions perfectly and that they fully understood the project goals and objectives. Kuen, Zailani and Fernando (2009) also suggested that competent project personnel are significant to direct project success. A competent project team comprised a project leader with its members, who are specifically selected, trained and possessed the required skills, knowledge and experience to handle the demands of the project. When the project is completed and later being introduced to the clients or end users, the ability of the team members to convince and sell the benefits of the project is important to ensure that the project is readily accepted by the clients.

Ngenoh (2014) sought to determine the challenges of implementing devolution and planning objectives by the Ministry of Planning and Devolution in Kenya. The research design for this study was a case study. The study used primary data which was collected using an interview guide. These respondents were deemed as key informants of the study because they were highly involved in the implementation of strategies in the ministry of devolution and planning and at the County Governments. The data obtained from the interview guide was analyzed qualitatively using content analysis. The study revealed that the ministry had developed mechanisms and strategy in achieving organizational objectives. The respondents indicated that the Ministry had made efforts in mobilizing resources from the government and its international development partners as well as the savings realized through better management of available resources.

According to Ackel et al. (2012), top management support and commitment ought to be regular, focused, inclusive and proactive through the implementation of the project. The technical decision regarding the project also ought to be made with due consultation. Therefore, project management and implementation is dependent on the top management support for direction and implementation of set goals. Werner et al. (2011) postulated that once a plan is well prepared and adopted it must be followed. To have it followed requires integrity and leadership. Cleland (2006) however suggested that project success is meaningful only if considered from two vantage points; the degree to which the project's technical performance objective was attained on time and within budget; the contribution that the project made to the strategic mission of the enterprise.

Vaidya, Sajeev and Callender (2006) found out in their study that top management support and performance measurement is critical. Successful projects require the use of effective 
internal integration strategies, such as use of outside technical expertise, selection of an experienced project manager, and selection of team members with significant previous work relationships.

Thomet and Vozza (2010) indicated that an M\&E system is an essential tool for results-based project management. It makes the project accountable to the target group, the stakeholders and the donor. It also contributes to organizational learning and to the improvement of projects. That learning can then be transferred and used in other locations and projects. A good evaluation strategy will ensure learning can be passed on to relevant cooperative organizations. Control and monitoring by cooperative members is an expression of responsibility for mutual learning, and provides feedback to other stakeholders. Furthermore Ramlall (2010) pointed out that tracking change is important as a tool for monitoring and evaluating the success of urban planning instruments. Through the establishment of performance indicators, urban planning instruments can be regularly assessed to determine whether they are in fact achieving urban sustainability or urban reform is required. Such indicators can include number of persons per doctor to assess social sustainability and even projected energy consumption rates to determine environmental sustainability.

Ragheb, El-Baghdady and Ayad (2012) supported that by stating that Monitoring and Evaluation (M\&E) is a significant instrument of management in urban planning practice. Its implementation on development projects and determining their priorities has immense prospects to assure successful performance of such plans. With social, economic, and public reforms and improvement of information systems, increasing attention has been paid to monitoring and evaluation in planning policy making, academic research, and practice. It is expected that such monitoring and evaluation will play more important roles in the future and lead to improvement in planning procedures and management.

According to Thomet and Vozza (2010), from the International Labour Organization, evaluation is essentially a reality test to assess the significance of the project. In particular, it looks at the efficiency, effectiveness, impact, sustainability and relevance of the project given its stated objectives. The manual further explains that monitoring is a core management responsibility. It involves collection, analysis and communication concerning the progress of the project and outputs achieved. It identifies actual and potential successes or failures as early as possible, and facilitates timely adjustments to what is being done. It enables the stakeholders to review progress and to propose action to achieve the objectives.

\subsection{METHODOLOGY}

The study utilized a descriptive survey research design. The target population comprised of 10 County Executive Committee Members, 22 County Chief Officers who report to CECs and 62 directorates of the respective functional sections or units of the government in Narok County. The study utilized a census technique of data collection meaning the target population was studied. A self-administered questionnaire containing open-ended and closed questions was used to obtain primary data while data was analysed using descriptive and inferential statistics.

\subsection{DATA PRESENTATION, ANALYSIS}

\subsection{Demographic Characteristics}

Results showed that $56(68 \%)$ respondents were male while $26(32 \%)$ were female. These results imply that most of the employees of Narok County Government are male. In terms of education level, the respondents were asked to indicate their level of education. Results 
showed that $50(61 \%)$ respondents had attained education up to post graduate level while 32 (39\%) respondents had attained education up to the first degree level. None of the respondents had education level below the first degree. This is an indicator that NCG has hired educated employees and thus has met the requirement of the Constitution of Kenya 2010. In another question, the respondents were asked to indicate their various roles performed in the county government of Narok. Results show that 57 (70\%) respondents served as directorates, $19(23 \%)$ respondents indicated that they served as County Chief Officers while only $6(7 \%)$ of the respondents indicated that they served as County Executive Committee members. These results can be explained by the fact that the total number of CECs is less than that of CCOs and directorates. In relation to period of service by the respondents results revealed that $64(78 \%)$ respondents had served in their current position for more than one year, $12(15 \%)$ respondents indicated that they had served in their current position for 6 months -1 year while only $6(7 \%)$ respondents indicated that that they had served in their current position for less than 3 months. This implies that most of the employees of NCG had served in their current position for about a year or more.

\subsection{Implementation of County Integrated Development Plans}

The study sought to find out the extent of implementation of the CIDP. The respondents were asked to indicate whether they were involved in the formulation of the County Integrated Development Plan (See Table 4.1).

Table 4.1: Formulation of the CIDP

\begin{tabular}{llc}
\hline Response & Frequency & Percent \\
\hline No & 16 & 19.5 \\
Yes & 66 & 80.5 \\
Total & 82 & 100 \\
\hline
\end{tabular}

Results show that $66(80.5 \%)$ respondents indicated that they were involved in the formulation of the CIDP while 16 (19.5\%) respondents disagreed.

\subsubsection{Extent of Implementation of the County Integrated Development Plans}

The respondents were also asked to indicate the extent to which the County Integrated Development Plan in NCG has been implemented. Results are presented in Table 4.4.

Table 4.2: Extent of Implementation of the CIDP

\begin{tabular}{lcc}
\hline Response & Frequency & Percent \\
\hline Low extent & 20 & 24.4 \\
Moderate extent & 56 & 68.3 \\
Great extent & 6 & 7.3 \\
Total & 82 & 100 \\
\hline
\end{tabular}

Results show that $56(68.3 \%)$ respondents indicated that the CIDP had been implemented to a moderate extent, $20(24.4 \%)$ respondents indicated that the CIDP had been implemented to a low extent while only $6(7.3 \%)$ respondents indicated that the CIDP had been implemented to a great extent.

\subsubsection{Performance Targets met by the NCG}

The respondents were asked to indicate the performance targets that the NCG met for the period 2013 - 2015 as shown in Table 4.3. 
Table 4.3: Performance Targets met by the NCG

\begin{tabular}{llc}
\hline Response & Frequency & Percent \\
\hline Less than $50 \%$ & 46 & 56.1 \\
Between $51 \%-75 \%$ & 36 & 43.9 \\
Total & 82 & 100 \\
\hline
\end{tabular}

Results show that $46(56.1 \%)$ respondents indicated that NCG had met less than $50 \%$ of the performance targets while $36(43.9 \%)$ respondents indicated that NCG had met $51 \%$ to $75 \%$ of the performance targets. This is an indicator that achievement of performance targets set in the annual work plan is very minimal.

\subsubsection{CIDP Development Projects and Intervention Completed}

The respondents were also asked to indicate what percentage of CIDP development projects or interventions their department has completed for the period 2013 - 2015 (See Table 4.4).

Table 4.4: Percentage of CIDP Development Projects and Intervention Completed

\begin{tabular}{llc}
\hline Response & Frequency & Percent \\
\hline Less than $50 \%$ & 48 & 58.5 \\
Between $51 \%-75 \%$ & 34 & 41.5 \\
Total & 82 & 100 \\
\hline
\end{tabular}

Results show that 48 (58.5\%) respondents indicated that their departments had completed less than $50 \%$ of CIDP development projects or interventions. Likewise, results also showed that $34(41.5 \%)$ of the respondents indicated that their departments have completed between $51 \%$ - 75\% CIDP development projects or interventions. This implies that completion of projects and interventions by the NCG was moderate. This contradicts the previous findings that the achievement of performance targets set in the annual work plan is very minimal. This can be explained by the fact that NCG could be undertaking projects and interventions that are not in the annual work plan and thus the disparity.

\subsubsection{Comprehensiveness of the CIDP}

The respondents were asked to indicate whether the County Integrated Development Plan of NCG is comprehensive as per the requirements of the constitution of Kenya 2010. Results are as presented in Table 4.5.

Table 4.5: Comprehensiveness of the CIDP

\begin{tabular}{llc}
\hline Response & Frequency & Percent \\
\hline No & 14 & 17.1 \\
Yes & 68 & 82.9 \\
Total & 82 & 100 \\
\hline
\end{tabular}

Results reveal that $68(82.9 \%)$ of the respondents agreed that the CIDP of NCG is comprehensive as per the requirements of the constitution of Kenya 2010. This reflects that the NCG was keen to adhere to the Kenya's constitution requirements.

The respondents were further asked to explain what aspects had the CIDP included. Results are as indicated in Table 4.6. 
Table 4.6: Aspects Included in the CIDP

\begin{tabular}{lcc}
\hline Response & Frequency & Percent \\
\hline Construction of infrastructure & 30 & 44.1 \\
Anchored on Vision 2030 & 14 & 20.6 \\
Awaits acceptance from the treasury & 10 & 14.7 \\
Advocates for gender balance & 9 & 13.2 \\
Encourages public participation & 5 & 7.4 \\
\hline
\end{tabular}

Results show that $30(44.1 \%)$ respondents indicated that the CIDP considered construction of infrastructure such as building of primary and ECD schools, roads and dispensaries. Results also show that $14(20.6 \%)$ respondents indicated that the CIDP was anchored on vision 2030. Further, the results revealed that $10(14.7 \%)$ respondents indicated that the CIDP became a working document after acceptance by the treasury. Results also showed that 9 (13.2\%) respondents indicated that the CIDP considered gender balance while 5 (7.4\%) respondents indicated that all departmental plans are integrated in the CIDP and also included the aspect of public participation. These results show that the NCG was keen to adhere to the Kenya's constitution requirements.

\subsubsection{Response of Departmental Executives to Strategic Objectives}

The respondents were asked to indicate whether the departmental executives of NCG respond to the strategic objectives in the CIDP (See Table 4.9).

Table 4.7: Response of Departmental Executives to Strategic Objectives

\begin{tabular}{llc}
\hline Response & Frequency & Percent \\
\hline No & 24 & 29.3 \\
Yes & 58 & 70.7 \\
Total & 82 & 100 \\
\hline
\end{tabular}

Results reveal that $58(70.7 \%)$ respondents indicated that departmental executives of NCG respond to the strategic objectives in the CIDP while $24(20.3 \%)$ respondents disagreed. This is an indicator that NCG executives respond to the strategic objective to a great extent.

The respondents were asked to explain how the departmental executives of NCG responded to the strategic objectives in the CIDP (See Table 4.10).

Table 4.8 Mode of Response to Strategic Objectives

\begin{tabular}{lcr}
\hline Response & $\begin{array}{r}\text { Freque } \\
\text { ncy }\end{array}$ & $\begin{array}{r}\text { Perc } \\
\text { ent }\end{array}$ \\
\hline Informed by social research & 18 & 31.0 \\
Formulation of sectoral and work plans & 15 & 25.9 \\
Execution of CIDP as part of budgetary plans & 12 & 20.7 \\
Deriving all budgetary planning from the CIDP Program Based Budget and & 11 & 19.0 \\
Medium Term Expenditure Program & & \\
Taking decisions together & 2 & 3.4 \\
\hline
\end{tabular}

Results revealed that $18(31 \%)$ respondents indicated that the CIDP was informed by social research with people involvement in grass root level. Results also indicated that $15(25.9 \%)$ respondents indicated that the departmental executives of NCG responded to the strategic 
objectives by drawing sectoral plans and work plans for implementing the CIDP. Results also revealed that $12(20.7 \%)$ respondents indicated that the departmental executives respond to strategic objectives through execution of CIDP as part of budgetary plans.

Further, results revealed that $11(19.0 \%)$ respondents indicated that the departmental executives respond to strategic objectives through deriving all budgetary planning from the CIDP, Program Based Budget and Medium Term Expenditure Program while 2 (3.4\%) respondents indicated that the departmental executives respond to strategic objectives through taking decisions together as the executive committee gives policy guidance that is discussed at the national assembly for posterity. This is an indicator that NCG executives respond to the strategic objective to a great extent.

\subsubsection{Organization Structure and Strategic Objectives}

The respondents were asked to indicate whether the current organization structure in NCG is able to deliver the strategic objectives in the CIDP. Table 4.9 presents the results.

Table 4.9: Ability of Organization Structure to Deliver Strategic Objectives

\begin{tabular}{llc}
\hline Response & Frequency & Percent \\
\hline No & 12 & 14.6 \\
Yes & 70 & 85.4 \\
Total & 82 & 100 \\
\hline
\end{tabular}

Results show that $70(85.4 \%)$ respondents indicated that the current organization structure in NCG is able to deliver the strategic objectives in the CIDP while $12(14.6 \%)$ respondents disagreed. This implies that the organization structure of NCG is well suited to deliver the strategic objectives as per the CIDP.

The respondents were also asked to explain how the current organization structure in NCG is able to deliver the strategic objectives in the CIDP. Results are as presented in Table 4.10.

Table 4.10: Way of Delivering Strategic Objectives

\begin{tabular}{lcc}
\hline Response & Frequency & Percent \\
\hline Role separation balance & 33 & 47.1 \\
Approving budgets for implementation of the CIDP & 9 & 12.9 \\
Having all administrative functions in departments in place & 10 & 14.3 \\
Separation of powers & 11 & 15.7 \\
Proper linkages with the grassroots & 7 & 10 \\
\hline
\end{tabular}

Results revealed that 33 (47.1\%) respondents indicated that the current organization structure in NCG is able to deliver the strategic objectives in the CIDP through role separation balance whereby the executive and legislature has created a harmonious relationship necessary for service delivery. Results also indicated that 9 (12.9\%) respondents indicated that the current organization structure in NCG is able to deliver the strategic objectives in the CIDP through approving budgets for implementation of the CIDP. Further, results revealed that $10(14.3 \%)$ respondents indicated that the current organization structure in NCG is able to deliver the strategic objectives in the CIDP through having all administrative functions in departments in place while $11(15.7 \%)$ respondents indicated that the current organization structure in NCG is able to deliver the strategic objectives in the CIDP through stipulating the mandate of each delivery unit thus the separation of powers. Results also showed that 7 (10\%) respondents 
indicated that the current organization structure in NCG is able to deliver the strategic objectives in the CIDP through proper linkages with the grassroots through ward representatives which enhances monitoring and evaluation of the CIDP programmes. This implies that the organization structure of NCG is well suited to deliver the strategic objectives as per the CIDP.

\subsection{Financial-Related Challenges}

The study sought to establish the financial-related challenges facing the implementation of the County Integrated Development Plan (CIDP) in Narok County Government. The respondents were asked to indicate whether NCG experienced financial-related challenges in the process of implementing the County Integrated Development Plan. Results are as presented in Table 4.11.

Table 4.11: Experience Financial-Related Challenges

\begin{tabular}{lcc}
\hline Response & Frequency & Percent \\
\hline No & 9 & 11 \\
Yes & 73 & 89 \\
Total & 82 & 100 \\
\hline
\end{tabular}

Results reveal that $73(89 \%)$ respondents indicated that the NCG experience financial-related challenges in the process of implementing the CIDP while 9 (11\%) respondents disagreed. This is an indicator that NCG indeed experienced financial-related challenges.

The respondent who indicated that NCG experienced financial-related challenges in the process of implementing the CIDP were asked to indicate the challenges. Table 4.12 shows the results.

\section{Table 4.12: Type of Financial-Related Challenges}

\begin{tabular}{lrc}
\hline Type of Financial-Related Challenge & $\begin{array}{l}\text { Frequ } \\
\text { ency }\end{array}$ & $\begin{array}{l}\text { Perc } \\
\text { ent }\end{array}$ \\
\hline $\begin{array}{l}\text { Lack of proper budgeting for the implementation of the County Integrated } \\
\text { Development Plan. }\end{array}$ & 28 & 38.4 \\
$\begin{array}{l}\text { Insufficient funds for the implementation of the County Integrated } \\
\text { Development Plan. }\end{array}$ & 60 & 82.2 \\
$\begin{array}{l}\text { Delay by the national government in disbursement of funds for the } \\
\text { implementation of the County Integrated Development Plan. }\end{array}$ & 73 & 100 \\
$\begin{array}{l}\text { Lack of direct control of finances under your authority for the } \\
\text { implementation of the County Integrated Development Plan. }\end{array}$ & 60 & 82.2 \\
\hline
\end{tabular}

Results reveal that $28(38.4 \%)$ respondents indicated that there was lack of proper budgeting for the implementation of the CIDP. Another 60 (82.2\%) respondents indicated that there existed the challenge of insufficient funds for the implementation of the CIDP. Results also showed that all the $73(100 \%)$ respondents indicated that there was delay by the national government in disbursement of funds for the implementation of the CIDP while 60 (82.2\%) respondents indicated that there existed the challenge of lack of direct control of finances by County Chief Officers (CCOs) whose core responsibility is the implementation of the CIDP. This is an indicator that NCG indeed experienced financial challenges which hinder the implementation of the CIDP.

Further, the respondents were asked to indicate whether NCG experience any other financial- 
Journal of Strategic Management

ISSN xxxx-Xxxx (Paper) ISSN XXXX-XXX (Online)

Vol.1, Issue 2 No.1, pp 1 - 23, 2017

www.ajpojournals.org

related challenges. Results are presented in Table 4.13.

Table 4.13: Other Financial-Related Challenges

\begin{tabular}{|c|c|c|}
\hline Response & Frequency & Percent \\
\hline No & 17 & 23.3 \\
\hline Yes & 56 & 76.7 \\
\hline Total & 73 & 100 \\
\hline
\end{tabular}

Results reveal that $56(76.7 \%)$ respondents indicated that NCG experience other financialrelated challenges while 17 (23.3\%) disagreed. Results on financial-related challenges are as presented in Table 4.14.

Table 4.14: Other Financial-Related Challenges

\begin{tabular}{lcc}
\hline Type of Financial-related Challenge & Frequency & Percent \\
\hline Poor collection of revenue. & 46 & 82.1 \\
Low resource mobilization and financial reserve collapses. & 40 & 71.4 \\
Bureaucratic financial processes. & 56 & 100 \\
Lack of funding for programmes and projects. & 50 & 89.3 \\
Poor prioritization of funding financial projects. & 42 & 75.0 \\
\hline
\end{tabular}

Results reveal that $46(82.1 \%)$ respondents indicated that they experienced the challenge of poor collection of revenue. Results also reveal that $40(71.4 \%)$ respondents indicated that they experienced the challenge of low resource mobilization and financial reserve collapses. Results further showed that $56(100 \%)$ respondents indicated that they experienced the challenge of bureaucratic financial processes while $50(89.3 \%)$ respondents indicated that they experienced the challenge of lack of funding for programmes and projects.

Further, results revealed that $42(75 \%)$ respondents indicated that they experienced the challenge of poor prioritization of funding financial projects. This is an indicator that NCG indeed experiences financial challenges which hinder the implementation of the CIDP.

\subsection{Human Resource-Related Challenges}

The study sought to establish the human resource-related challenges facing the implementation of the County Integrated Development Plan (CIDP) in Narok County Government. The respondents were asked to indicate whether NCG experience human resource-related challenges in the process of implementing the CIDP. Results are as shown in Table 4.15.

Table 4.15: Experience Human Resource-Related Challenges

\begin{tabular}{lcc}
\hline Response & Frequency & Percent \\
\hline No & 15 & 18.3 \\
Yes & 67 & 81.7 \\
Total & 82 & 100 \\
\hline
\end{tabular}

Results revealed that $67(81.7 \%)$ of the respondents indicated that the NCG experience human resource-related challenges in the process of implementing the CIDP while 15 (18.3\%) respondents disagreed. This is an indicator that NCG indeed experienced human resource challenges in the process of implementing the CIDP. The respondent who indicated that NCG experienced human resource-related challenges in the process of implementing the 
CIDP were asked to indicate the challenges. Results are as presented in Table 4.16.

Table 4.16: Type of Human Resource-Related Challenges

\begin{tabular}{lll}
\hline Type of Human Resource-Related Challenge & $\begin{array}{l}\text { Frequ } \\
\text { ency }\end{array}$ & $\begin{array}{l}\text { Perc } \\
\text { ent }\end{array}$ \\
\hline $\begin{array}{l}\text { Lack of relevant skills required in the implementation of the County } \\
\text { Integrated Development Plan. }\end{array}$ & 58 & 86.6 \\
Lack of a proper employee development system. & 54 & 80.6 \\
Absence of performance measurement system for the employees. & 54 & 80.6 \\
Poor reward system for employee performance. & 50 & 74.6 \\
$\begin{array}{l}\text { Failure to follow the project management approach in the implementation of } \\
\text { the County Integrated Development Plan. }\end{array}$ & 56 & 83.6 \\
\hline
\end{tabular}

Results reveal that $58(86.6 \%)$ respondents indicated that they lacked relevant skills required in the implementation of the CIDP, $54(80.6 \%)$ respondents indicated that there existed the challenge of lack of a proper employee development system and absence of performance measurement system for the employees respectively. Further, results revealed that $50(74.6 \%)$ respondents indicated that there existed a poor reward system for employee performance while $56(83.6 \%)$ respondents indicated that there existed the challenge of failure to follow the project management approach in the implementation of the CIDP. This is an indicator that NCG indeed experienced human resource challenges in the process of implementing the CIDP.

Further, the respondents were asked to indicate whether NCG experience any other human resource-related challenges. Results are as presented in Table 4.17.

Table 4.17: Other Human Resource-Related Challenges

\begin{tabular}{lcc}
\hline Response & Frequency & Percent \\
\hline No & 15 & 22.4 \\
Yes & 52 & 77.6 \\
Total & 67 & 100 \\
\hline
\end{tabular}

Results reveal that $52(77.6 \%)$ respondents indicated that NCG experiences other human resource-related challenges while 15 (22.4\%) disagreed. Results on other human resourcerelated challenges are as presented in Table 4.18.

Table 4.18: Other Human Resource-Related Challenges

\begin{tabular}{lcc}
\hline Type of Human resource-related Challenge & Frequency & Percent \\
\hline Lack of training forums to build up capacity of personnel. & 51 & 98.1 \\
Disparity of salary scales between the old and new employees. & 50 & 96.1 \\
Inadequate technical personnel. & 46 & 88.5 \\
Lack of staff induction/orientation for skills development. & 41 & 78.8 \\
Lack of skill alignment. & 46 & 88.5
\end{tabular}

Results revealed that 51 (98.1) respondents indicated that NCG experienced the challenge of lack of training forums to build up capacity of personnel. Results also showed that 50 (96.1\%) respondents indicated that NCG experienced the challenge of disparity of salary scales between the old and new employees while $46(88.5 \%)$ respondents indicated that NCG experienced the challenge of inadequate technical personnel. Further, results showed that 41 
(78.8\%) respondents indicated that $\mathrm{NCG}$ experienced the challenge of lack of staff induction/orientation for skills development while $46(88.5 \%)$ respondents indicated that NCG experienced the challenge of lack of skill alignment. His study identified effective factors, like: leadership, organizational structure, human resources, information systems and technology, on successful implementation of strategies in service sector.

\subsection{Leadership-Related Challenges}

The study sought to establish the leadership-related challenges facing the implementation of the CIDP in Narok County Government. The respondents were asked to indicate whether NCG experienced leadership-related challenges in the process of implementing the CIDP. Results are as presented in Table 4.19 below.

Table 4.19: Experience Leadership-Related Challenges

\begin{tabular}{lcc}
\hline Response & Frequency & Percent \\
\hline No & 20 & 24.4 \\
Yes & 62 & 75.6 \\
Total & 82 & 100 \\
\hline
\end{tabular}

Results reveal that $62(75.6 \%)$ of the respondents indicated that the NCG experienced leadership-related challenges in the process of implementing the CIDP while $20(24.4 \%)$ respondents disagreed. This is an indicator that NCG indeed experienced leadership challenges in the process of implementing the CIDP. Findings indicated that the organization leadership at NSSF is not effective and this may have led to poor strategy implementation.

The respondents who indicated that NCG experienced leadership-related challenges in the process of implementing the CIDP were asked to indicate the challenges. Table 4.20 shows the results.

\section{Table 4.20: Type of Leadership-Related Challenges}

\begin{tabular}{lrc}
\hline Type of Leadership-Related Challenge & $\begin{array}{c}\text { Frequ } \\
\text { ency }\end{array}$ & $\begin{array}{c}\text { Perc } \\
\text { ent }\end{array}$ \\
\hline Lack of ethical and moral conduct. & 26 & 41.9 \\
Lack of clear vision articulation to foster the implementation of the CIDP. & 36 & 58.1 \\
$\begin{array}{l}\text { Lack of inspiration and motivation to the employees involved in the } \\
\text { implementation of the CIDP. }\end{array}$ & 52 & 83.9 \\
$\begin{array}{l}\text { Lack of clear policies to conduct monitoring and evaluation geared towards } \\
\text { successful implementation of the CIDP. }\end{array}$ & 56 & 90.3 \\
$\begin{array}{l}\text { Corruption and nepotism among the senior management. } \\
\text { Lack of proper coordination among the departments involved in the }\end{array}$ & 38 & 61.3 \\
$\begin{array}{l}\text { implementation of the CIDP. } \\
\text { Lack of effective top-down and up-down communication. }\end{array}$ & 44 & 71.0 \\
\hline
\end{tabular}

Results reveal that $26(41.9 \%)$ respondents indicated that there existed the challenge of lack of ethical and moral conduct, $36(58.1 \%)$ respondents indicated that there existed the challenge of lack of clear vision articulation to foster the implementation of the CIDP, while $52(83.9 \%)$ respondents indicated that there existed the challenge of lack of inspiration and motivation to the employees involved in the implementation of the CIDP. Results also reveal that $56(90.3 \%)$ respondents indicated that there existed the challenge of lack of clear policies to conduct monitoring and evaluation geared towards successful implementation of the CIDP, 
$38(61.3 \%)$ respondents indicated that there existed the challenge of corruption and nepotism among the senior management, $44(71 \%)$ respondents indicated that there existed the challenge of lack of proper coordination among the departments involved in the implementation of the CIDP, while $50(80.6 \%)$ respondents indicated that there existed the challenge of lack of effective top-down and up-down communication. This is an indicator that NCG indeed experienced leadership challenges in the process of implementing the CIDP.

Further, the respondents were asked to indicate whether NCG experience any other leadership-related challenges. Results are as presented in Table 4.21.

Table 4.21: Other Leadership-Related Challenges

\begin{tabular}{lcc}
\hline Response & Frequency & Percent \\
\hline No & 22 & 35.5 \\
Yes & 40 & 64.5 \\
Total & 62 & 100 \\
\hline
\end{tabular}

Results reveal that 40 (64.5\%) respondents indicated that NCG experienced other leadershiprelated challenges, while $22(35.5 \%)$ did not agree. Table 4.24 below shows the other leadership-related challenges that NCG experienced.

Table 4.22: Other Leadership-Related Challenges

\begin{tabular}{lcc}
\hline Type of Leadership-related Challenge & Frequency & Percent \\
\hline Poor planning and prioritisation of development intervention. & 36 & 90 \\
Political influence especially based on clans. & 36 & 90 \\
External political opposition. & 26 & 65 \\
Insubordination. & 19 & 47.5 \\
Unequal distribution of resources and inability to plan. & 32 & 80 \\
\hline
\end{tabular}

Results revealed that $36(90 \%)$ respondents indicated that NCG experienced the challenge of poor planning and prioritisation of development intervention. Results also revealed that 36 (90\%) respondents indicated that NCG experienced the challenge of political influence especially based on clans, while $26(65 \%)$ respondents indicated that NCG experienced the challenge of external political opposition which fails to create space for service delivery during the transition period. Further, results revealed that 19 (47.5\%) respondents indicated that NCG experienced the challenge of exclusiveness of the system of governance and insubordination, while $32(80 \%)$ respondents indicated that NCG experienced the challenge of unequal distribution of resources and inability to plan.

\subsubsection{National Government Policy and Legislations}

The respondents were asked to indicate whether the national government policy and legislations influence the implementation of the County Integrated Development Plan. Results are as shown in Table 4.23.

Table 4.23: Influence of National Government Legislation and Policy

\begin{tabular}{|c|c|c|}
\hline Response & Frequency & Percent \\
\hline No & 14 & 17.1 \\
\hline Yes & 68 & 82.9 \\
\hline Total & 82 & 100 \\
\hline
\end{tabular}


Results reveal that $68(82.9 \%)$ respondents indicated that the national government policy and legislations influence the implementation of the CIDP, while 14 (17.1\%) respondents disagreed. To support their answer, the respondents indicated that the national government policy and legislations influence the implementation of the CIDP both negatively and positively (See Tables 4.24 and 4.25).

Table 4.24: Negative Influence of National Government Legislation and Policy

\begin{tabular}{lcc}
\hline Negative Influence & Frequency & Percent \\
\hline Delaying of funds allocated to counties by national government. & 68 & 100 \\
Delay in service delivery. & 62 & 91.2 \\
Hinders public finance management. & 51 & 75 \\
Lack of oversight from national government to county government. & 45 & 66.2 \\
Lack of clear policy. & 59 & 86.8 \\
\hline
\end{tabular}

Results reveal that $68(100 \%)$ respondents indicated that national government policy and legislations caused delay of funds allocated to counties by national government. Results also revealed that $62(91.2 \%)$ respondents indicated that national government policy and legislations caused delay in service delivery, while 51 (75\%) respondents indicated that national government policy and legislations hindered public finance management. Further, results revealed that $45(66.2 \%)$ respondents indicated that national government policy and legislations caused lack of clear policy as to how devolution is supposed to be managed, while $59(86.8 \%)$ respondents indicated that national government policy and legislations caused lack of oversight by national government to county government.

Table 4.25: Positive Influence of National Government Legislation and Policy

\begin{tabular}{lcc}
\hline Positive Influence & Frequency & Percent \\
\hline CIDP must be aligned with the national government policies. & 42 & 61.8 \\
Consistency with Vision 2030 and COK 2010. & 41 & 60.3 \\
\hline
\end{tabular}

Results revealed that $42(61.8 \%)$ respondents indicated that national government policy and legislations enhances alignment of the CIDP with the national government policies as much as it addresses the Narok people aspirations. Results also revealed that $41(60.3 \%)$ respondents indicated that national government policy and legislations helped to ensure that the CIDP is consistent with the Vision 2030 and COK 2010. These findings are supported by the assertion that the Kenya Vision 2030 blueprint and the resultant second medium term plan places significant emphasis on CIDP as a framework for the development of counties.

\subsubsection{NCG Formulated Policies and Enacted Laws}

The respondents were also asked to indicate whether the NCG had formulated policies and enacted laws that govern effective implementation of the CIDP. Results are as presented in Table 4.26.

Table 4.26: NCG Formulated Policies and Enacted Laws

\begin{tabular}{lcc}
\hline Response & Frequency & Percent \\
\hline No & 48 & 58.5 \\
Yes & 34 & 41.5 \\
Total & 82 & 100 \\
\hline
\end{tabular}

Results reveal that only 34 (41.5\%) respondents indicated that NCG had formulated policies 
and enacted laws that govern effective implementation of the CIDP while 48 (58.5\%) respondents disagreed. The respondents also noted that NCG had formulated policies and enacted laws such as finance bill for management of Bursary board and Maasai Mara Community Fund, forest bill and water bill, investment conference policy and cooperative development funds policy, annual appropriation act and Finance Act, FIF bills, Narok town integrated plan and fiscal policies.

\subsubsection{Organization Culture}

The respondents were asked to indicate whether organization culture of NCG influenced the implementation of the County Integrated Development Plan. Table 4.27 shows the results.

Table 4.27: Influence of Organization Culture

\begin{tabular}{lcc}
\hline Response & Frequency & Percent \\
\hline No & 23 & 28 \\
Yes & 59 & 72 \\
Total & 82 & 100 \\
\hline
\end{tabular}

Results show that $59(72 \%)$ respondents indicated that the organization culture influenced the implementation of the CIDP, while 23 (28\%) respondents disagreed.

Further, the respondents were asked to explain how organization culture of NCG influenced the implementation of the County Integrated Development Plan. In response, the respondents indicated that organization culture of NCG had both positive and negative influence on the implementation of the CIDP (See Table 4.28 and 4.29).

Table 4.28: Positive Influence of Organization Culture

\begin{tabular}{lcc}
\hline Positive Influence & Frequency & Percent \\
\hline Allowed the departments to participate in development of CIDP. & 42 & 71.2 \\
Provides conducive environment for implementation of the CIDP. & 45 & 76.3 \\
\hline
\end{tabular}

Results reveal that $42(71.2 \%)$ respondents indicated that organization culture allowed the departments to participate in development of CIDP document. Results also revealed that 45 (76.3\%) respondents indicated that organization culture provided a conducive environment for implementation of the CIDP.

Table 4.29: Negative Influence of Organization Culture

\begin{tabular}{lcc}
\hline Negative Influence & Frequency & Percent \\
\hline Existence of many cultures in NCG. & 42 & 71.2 \\
Bureaucracy. & 12 & 20.3 \\
Hindrance of monitoring and evaluation. & 41 & 69.5 \\
Uncertainty of future political environment & 16 & 27.1 \\
Lack of provision for departmental autonomy in decision making & 45 & 76.3 \\
\hline
\end{tabular}

Results revealed that $42(71.2 \%)$ respondent indicated that NCG is a cosmopolitan county and has varied cultures. Results also revealed that 12 (20.3\%) respondent indicated that the organization culture is bureaucratic and shows culture that does not embrace effective public customer service, while $41(69.5 \%)$ respondents indicated that the organization culture does not allow for monitoring and evaluation, which results in poor performance and lack of 
commitment. Further, results revealed that 16 (27.1\%) respondents indicated that the organization culture causes uncertainty of future political environment, which fuels an uneasy culture that enforces corruption at the expense of service delivery, while $45(76.3 \%)$ respondents indicated that the organization culture lacks provision for departmental autonomy in decision making on funds for projects.

\subsection{Inferential Statistics}

\subsubsection{Chi-Square Tests}

To show the relationship between the independent and dependent variables, the study conducted chi-square tests. Table 4.30 presents the results of the chi square test.

\section{Table 4.30: Chi Square Statistics}

Extent of

Implementation of the

CIDP

\begin{tabular}{|c|c|c|c|c|c|c|}
\hline & & $\begin{array}{l}\text { Lo } \\
\text { w } \\
\text { exte } \\
\text { nt }\end{array}$ & $\begin{array}{l}\text { Mode } \\
\text { rate } \\
\text { extent }\end{array}$ & $\begin{array}{l}\text { Grea } \\
\mathrm{t} \\
\text { exte } \\
\text { nt }\end{array}$ & $\begin{array}{l}\mathrm{T} \\
\text { ot } \\
\text { al }\end{array}$ & $\begin{array}{l}\text { Chi } \\
\text { Square }\end{array}$ \\
\hline $\begin{array}{l}\text { Does NCG experience financial-related challenges } \\
\text { in the process of implementing the County } \\
\text { Integrated Development Plan? }\end{array}$ & $\begin{array}{l}\mathrm{N} \\
\mathrm{o}\end{array}$ & 9 & 4 & 2 & $\begin{array}{l}1 \\
5\end{array}$ & $\begin{array}{l}X^{2}=15.6 \\
96 \\
(p=0.00 \\
0)\end{array}$ \\
\hline & $\begin{array}{l}\mathrm{Y} \\
\mathrm{e} \\
\mathrm{s}\end{array}$ & 11 & 52 & 4 & $\begin{array}{l}6 \\
7\end{array}$ & \\
\hline Total & & 20 & 56 & 6 & $\begin{array}{l}8 \\
2\end{array}$ & \\
\hline $\begin{array}{l}\text { Does NCG experience human resource-related } \\
\text { challenges in the process of implementing the } \\
\text { County Integrated Development Plan? }\end{array}$ & $\begin{array}{l}\mathrm{N} \\
\mathrm{o}\end{array}$ & 9 & 4 & 2 & $\begin{array}{l}1 \\
5\end{array}$ & $\begin{array}{l}X^{2}=15.1 \\
10 \\
(p=0.00 \\
1)\end{array}$ \\
\hline & $\begin{array}{l}\mathrm{Y} \\
\mathrm{e} \\
\mathrm{s}\end{array}$ & 11 & 52 & 4 & $\begin{array}{l}6 \\
7\end{array}$ & \\
\hline Total & & 20 & 56 & 6 & $\begin{array}{l}8 \\
2\end{array}$ & \\
\hline $\begin{array}{l}\text { Does NCG experience leadership-related challenges } \\
\text { in the process of implementing the County } \\
\text { Integrated Development Plan? }\end{array}$ & $\begin{array}{l}\mathrm{N} \\
\mathrm{o}\end{array}$ & 10 & 9 & 1 & $\begin{array}{l}2 \\
0\end{array}$ & $\begin{array}{l}X^{2}=9.40 \\
8 \\
(p=0.00 \\
9)\end{array}$ \\
\hline & $\begin{array}{l}\text { Y } \\
\text { e } \\
\text { s }\end{array}$ & 10 & 47 & 5 & $\begin{array}{l}6 \\
2\end{array}$ & \\
\hline Total & & 20 & 56 & 6 & $\begin{array}{l}8 \\
2\end{array}$ & \\
\hline $\begin{array}{l}\text { Does the national government policy and } \\
\text { legislations influence the implementation of the }\end{array}$ & $\begin{array}{l}\mathrm{N} \\
\mathrm{o}\end{array}$ & 11 & 2 & 1 & $\begin{array}{l}1 \\
4\end{array}$ & $\begin{array}{l}X^{2}=27.5 \\
31\end{array}$ \\
\hline
\end{tabular}


County Integrated Development Plan?

$(\mathrm{p}=0.00$

\begin{tabular}{|c|c|c|c|c|c|c|}
\hline & Y & 9 & 54 & 5 & $\begin{array}{l}6 \\
8\end{array}$ & 0) \\
\hline & $\mathrm{S}$ & & & & & \\
\hline Total & & 20 & 56 & 6 & $\begin{array}{l}8 \\
2\end{array}$ & \\
\hline \multirow[t]{2}{*}{$\begin{array}{l}\text { Does the organization culture of NCG influence the } \\
\text { implementation of the County Integrated } \\
\text { Development Plan? }\end{array}$} & $\begin{array}{l}\mathrm{N} \\
\mathrm{O}\end{array}$ & 13 & 8 & 2 & $\begin{array}{l}2 \\
3\end{array}$ & $\begin{array}{l}\mathrm{X}^{2}=18.8 \\
70 \\
(\mathrm{P}=0.00 \\
0)\end{array}$ \\
\hline & $\begin{array}{l}\mathrm{Y} \\
\mathrm{e}\end{array}$ & 7 & 48 & 4 & $\begin{array}{l}5 \\
9\end{array}$ & \\
\hline Total & & 20 & 56 & 6 & $\begin{array}{l}8 \\
2\end{array}$ & \\
\hline
\end{tabular}

The study sought to establish the influence of financial-related challenges on the implementation of the CIDP in NCG. Results show that the relationship between financialrelated challenges and implementation of CIDP was significant $\left(X^{2}=15.696, p=0.000\right)$. This implies that financial-related challenges influence the implementation of CIDP in Narok County Government. The study sought to establish the influence of human resource-related challenges on the implementation of the CIDP in NCG. Results also showed that the relationship between human resource-related challenges and implementation of CIDP was significant $\left(\mathrm{X}^{2}=15.110, \mathrm{P}=0.001\right)$. This implies that human resource-related challenges influence the implementation of CIDP in Narok County Government. The study sought to establish the influence of leadership-related challenges on the implementation of the CIDP in NCG. Results show that the relationship between leadership-related challenges and implementation of CIDP was significant $\left(\mathrm{X}^{2}=9.408, \mathrm{P}=0.009\right)$. This implies that leadershiprelated challenges influence the implementation of CIDP in Narok County Government. The study sought to establish the influence of national government policy and legislations on the implementation of the CIDP in NCG. Results revealed that the relationship between the national government policy and legislations and implementation of CIDP was significant $\left(\mathrm{X}^{2}=27.531, \mathrm{P}=0.000\right)$. This implies that the national government policy and legislations influences the implementation of CIDP in Narok County Government. The study sought to establish the influence of organization culture on the implementation of the CIDP in NCG. Results revealed that the relationship between the organization culture of NCG and implementation of CIDP was significant $\left(\mathrm{X}^{2}=18.870, \mathrm{P}=0.000\right)$. This implies that the organization culture of NCG influences the implementation of CIDP in Narok County Government.

\subsection{CONCLUSIONS AND RECOMMENDATIONS}

\subsection{Conclusions}

Based on the findings, the study concluded that NCG had implemented the CIDP to a moderate extent. The study also concluded that financial-related challenges, human resourcerelated challenges, leadership-related challenges, national government policy and legislations and organization culture of NCG had a significant relationship with the implementation of the CIDP in NCG. 


\subsection{Recommendations}

Based on the study findings, it was evident that delay by the national government in disbursement of funds for the implementation of the CIDP was the most pertinent financial challenge. Drawing from these findings, the study recommends that the national government of Kenya should negate from delaying disbursement of funds to the county governments. This would assist to ensure that county governments implement their CIDP as stipulated in their budgets and within the stipulated timeline.

The study findings revealed that the most pertinent human resource-related challenge was lack of training forums to build up capacity of personnel. The study therefore recommends that NCG should come up with proper human resource policies which have provision for capacity building through training. This would ensure that the employees are competent, which would translate to better performance and successful implementation of the CIDP.

Drawing from the findings that political influence especially based on clans was the most significant leadership challenge that NCG encountered, the study recommends that NCG should review their style of leadership to a transformational and consultative style. This would help to curb the challenge of political interference, and as a result the process of implementing the CIDP would become effective.

Results revealed that national government policies and legislations influenced the implementation of the CIDP. The study thus recommends that the national government should review the national legislations and policies that govern the operations of county governments. The national governments should focus on revising the policies and legal framework to reduce the much interference that is caused by the bureaucratic procedures of government. It should also focus on ensuring that it enacts laws that adhere to the constitution of Kenya. This would make the process of implementing the CIDP easier and thus improve on performance of governments.

\section{REFERENCES}

Akwara, J. (2010). Challenges of strategy implementation at the Ministry of Co-operative Development and Marketing (Unpublished master's thesis). University of Nairobi, Nairobi, Kenya.

Busaka, J., \& Kwasira, J. (2015). An assessment of challenges influencing strategy implementation in public sector organizations in Kenya: A case of betting control and licensing board. International Journal of Research in Applied Natural and Social Sciences, 3(10), 12-22.

Covin, J. G., Slevin, D. P., \& Schulz, R. L. (2004). Implementing strategic mission: Effective strategic, structural and tactical choices. Journal of Management Studies, 31(2), 481505.

Jofre, L. D. (2011). Successfully implementing strategic decisions. Long Range Planning, 18(3), 91-97.

Kirui, S. (2013). Factors influencing implementation of strategic plans in local authorities in Migori County (Unpublished master's thesis). Kenyatta University, Nairobi, Kenya. 
Journal of Strategic Management

Liedtka, J. M. (2008). Linking strategic thinking with strategic planning. Strategy and Leadership, $26(2)$ 30-36.

Mbambisa, M. (2014). Nelson Mandela Bay Municipality: Integrated Development Plan. Retrieved from http://www. localgovernmentaction. org/xh/content/integrateddevelopment-plan

Polle, E. (2012). Challenges of strategy implementation facing audit firms in Nairobi (Unpublished master's thesis). University of Nairobi, Nairobi, Kenya.

Wade, M., \& Hulland, J. (2004). The resource-based view and information systems research: review, extension, and suggestions for future research. MIS Quarterly, 28(1), 107142. 